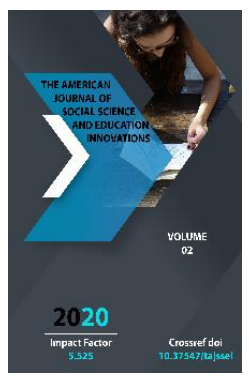

\title{
The Role Of Innovation In Scientific Creation
}

\section{Muhitdin Nazarov}

Andijan Machine Building Institute Department Of "Humanities" Candidate Of Philosophical Sciences,, Uzbekistan

Journal Website:

http://usajournalshub.c

om/index,php/tajssei

Copyright: Original

content from this work

may be used under the

terms of the creative

commons attributes

4.0 licence.

\section{ABSTRACT}

The article describes the phenomenon of innovation, its place in scientific creativity, the method of innovation in scientific and technical research and its heuristic basis. As a socio-cultural phenomenon focused on innovation, innovation is interpreted as a product of the creative-theoretical and practical activity of the subject.

\section{KEYWORDS}

Innovation, phenomenon, scientific creation, technique, technology, subject, invention, discovery, innovation.

\section{INTRODUCTION}

Innovative processes play an important role in the development of modern science. The efficiency of the productive forces is directly proportional to the progress of science.

President Mirziyoyev said: "The future of the new Uzbekistan is based on science and innovation. As we aim to turn Uzbekistan into a developed country, we can achieve this only through rapid reforms, science and innovation. "[1]

This article is devoted to the use of innovative methods in modern technical and technological research. Contemporary researchers NT Balabanov, GA Krayukhin, LF Shabanova, B. Santo, IV Bestujev-Lada, N. Shermuhammedova, L. Kurbanova and others The content of scientific creativity, innovative methods and processes and elaborated on its essence in his scientific research. In this article, we have looked at the innovation method as a novelty-oriented phenomenon and shown that it is based on heuristic ideas that determine the direction of development. Because in the natural-historical process, innovative ideas are manifested as unique phenomena. 


\section{THE MAIN PART}

The translation of the word innovation means renewal, change. The phenomenon of innovation, according to its heuristic basis, is, firstly, focused on innovation, that is, on the discovery of cultural innovations, and secondly, it reflects the present day of culture as a socio-cultural phenomenon. Innovation is also interpreted as a product of the subject's creative-theoretical and subject-practical activities.

According to IT Balabanov, "Innovation is a materialized result achieved by investing in new equipment or technology, labor production, services and management, as well as new forms of organization of control, accounting, planning, analysis, etc." [ 2]

There are three components to the innovation process in the modern literature. The first of these, the subjective, creative (creative), practical (labor) components are studied separately. In particular, it is clear that today in the culture of creativity the importance of labor is growing, it is becoming more creative, innovation is manifested as a socio-cultural model of objectification of innovation. Because the originality of modern sociocultural creativity is determined by communicative innovations. Its widespread use in culture leads to the virtualization and globalization of the socio-cultural system. Today, innovation is widely used in various fields of culture, transcending technical and economic boundaries. This situation is also reflected in science, which is the product of scientific and creative activity.

At present, innovation is considered as the main source of research activities. It is known that innovation is a complex socio-cultural phenomenon. Innovation as a socio-cultural phenomenon embodies all the trends of culture. Innovation is also based on heuristic ideas that determine the future of culture by itself as an innovation-oriented phenomenon. If we pay special attention to innovations in scientific and creative activity, it is impossible to imagine scientific research without them, because they are manifested as unique phenomena. In this sense, their causes are not sufficiently defined and can only be assessed on the basis of their heuristic nature, not for some reason, not always, not for the most part, not for any law. That is why W. Wellell writes: "Previous truths are not expelled, not rejected, but expanded, and the history of each science is truly innovative" [3]. However, Dugel hypothesized that in many cases where science did not emerge in space, the new scientific idea certainly had its source, meaning that every rise in science was gradual on the basis of new innovations and innovations, along with traditional scientific ideas. In general, with innovation, the achievements made on the basis of scientific and creative activity can be slightly modified. But they cannot be completely ruled out, that is, new hypotheses emerge on the basis of a wide range of innovations and innovations. But we also cannot deny that there have been slow and successive changes in the development of science. Indeed, many scientific advances have not relied on theories or hypotheses that preceded them. This process is especially true of "premature" scientific discoveries.

According to SE Kryuchkova, innovation is a paradigmatic activity aimed at updating existing forms and methods of scientific and creative activity, creating new goals and means for their implementation. It creates important conditions for the development of the full potential of the scientist, his readiness for any, even unexpected situations, his ability to quickly adapt to new situations [4].

A. Osborne recommends the method of "brainstorming" to describe the scientific and 
creative process in the field of technology. Its essence is to have a specific influence on the thinking process of the scientist or group solving the problem. Successful resolution of unresolved problems in individual attempts during brainstorming is possible only if the four principles are followed.

1) the possibility of any criticism, that is, the fact that any opinion should be expressed even if it is wrong;

2) to encourage any unexpected thought, the more unnatural the idea, the better;

3) how many and varied the ideas presented should be;

4) that the said idea does not belong to anyone, that is, it can be added, changed, perfected to other ideas as everyone wishes.

Modern views on scientific and creative activity pay more attention to its innovative components. That is why now creative activity is understood as an innovative way of human activity aimed at creating new material and spiritual values and focusing on social significance. In this sense, scientific creativity, which is a special form of creativity, also has a unique innovative character. Its main task is to innovate the real possibilities and objects of events.

Currently, the state of development of scientific and creative activity in the country and its structural changes are closely linked with innovation. In particular, the role of innovation in the introduction of innovations in the production and service sectors of science is invaluable. Therefore, in order to ensure the development of science and technology in our country, it is important to create an innovative environment and constantly encourage heuristic activities.

The concepts of "discovery" and "invention" are closely related to innovation. At the heart of this connection are the concepts of "new" and "creation", which are important for a number of these concepts. All the phenomena recorded together with these concepts are to some extent the product of creation. After all, they are created, formed in a creative process, and their integral description is innovation.

Innovation serves the purposeful orientation of innovations in various spheres of human life, while maintaining the dynamic unity of experience and innovation accumulated on the basis of scientific and creative activity. It also plays a methodological role in the free development of new theories, adhering to the principle of succession [5].

Naturally, discovery, invention, innovation are a kind of phenomenon. However, in the first of them the individual-personal aspect, and in the last the socio-cultural aspect is decisive. Speaking about the nature of discovery and innovation, K. Findley and C. Lamsden write: "We do not limit the criteria of discovery from the beginning. However, it must meet the requirements of innovation and be in line with the socio-cultural dimension of the competition. "[6]

In addition, these experts continue: "Innovation is any invention that is recognized to a certain extent by society. In order to evaluate an invention as an innovation, it must be possible to translate it. "[7] Thus, in the discovery-innovation pair, discovery manifests itself as the product of a creative process that takes place at the stage of high innovation, which is close to the absolute on an individual level, and innovation as the product of a creative process that takes place at a sociocultural level.

While these phenomena are interconnected and interacting, no discovery can be an innovation. According to E.N. Knyazeva, in many cases, the discovery remains a novelty in itself or has a limited range of broadcasting and changes only the local environment necessary for future research [8]. But any innovation is not a new discovery. For 
example, what already exists is the creation of an improved modification of events. In a comparative analysis of discoveries and innovations, IT Balabanov describes their differences as follows:

- "Discovery, as well as invention, as a rule, is carried out at a fundamental level. Innovation is created in a technological (practical) way.

- The discovery can be made only by the inventor. Innovation is developed by the team (laboratories, departments of the institute) and put into practice as an innovative project.

- The purpose of the discovery is not intended. Innovation, on the other hand, will always be aimed at obtaining significant benefits, in particular, large sums of money, increasing labor efficiency by introducing some innovation in machinery and technology, reducing the cost of production.

- Discovery can happen by accident, and innovation is always the result of research, and it can not be developed suddenly. Innovation requires a clear goal and feasibility study "[1].

An invention is a kind of "gap" between discovery and innovation. If the discovery is the product of creative activity in accordance with the requirements of the market, the invention represents the various technical and technological products of human creative activity, while the discovery of previously unknown phenomena in nature.

This concept has a practical character in relation to the concept of "discovery", and with the concept of "innovation", on the contrary, has a research character. G. A. Krayukhin and L. F. Shaybakova writes: "The concept of discovery is inextricably linked with research activities, and the concept of innovation emerges at the stage of practical application of research results. This is determined by changes in products and production processes themselves. "[9]

An invention occurs within a specific discovery and can grow to the level of innovation. In order to gain a deeper understanding of the concept of "innovation", it is expedient to compare it with the concept of "change". It should be noted that Shumpeter introduced the tradition of determining the content of innovation through change, and such an interpretation is common in the modern scientific literature.

At the same time, it should not be overlooked that one of the main functions of innovation and innovative activity is change. However, even in this case, when we say change, we must first mean positive change. In this regard, B. Santo writes: "Innovation is any goal-oriented positive change of the material and intangible elements of the organization, that is, such a change serves the development and growth of the organization" [10]. Second, change must be specific to the attribute qualities of the innovation, not to the innovation itself. In this regard, I. BestujevLada said: "the introduction of innovation is a form of management decision, which means a significant change in a particular process, event (technical, economic, political, social)" [11].

At the same time, it is necessary to distinguish between the direct change that innovation brings and the change that arises as a result, that is, the change that arises from the first case and does not apply to the field in which innovation is applied. In our opinion, it would be correct to talk about the interdependence of the concepts of "change" and "innovation". Indeed, as noted above, innovation and innovation are synonymous in a number of studies. However, even in this case, innovation is a concept subject to "change". For example, $\mathrm{H}$. Barnett interpreted innovation as the main mechanism of cultural change processes [12]. 
According to Al Prigogin, "innovation as a special mechanism has its place in many goaloriented changes" [13]. Thus, the analysis of the genesis of the concept of innovation and its definitions in the modern literature allows us to emphasize innovation as a mechanism for introducing external factors into culture in culture discourse and objectively innovating in the XXI century in the context of technical and economic problems. .

While the semantic analysis of the interaction of innovation with the concepts of "invention" and "discovery" reflects its creativetheoretical aspect, such an analysis of the interaction of innovation with innovation - the subject-practical nature, its application to the concepts of "change" and "innovation" reveals the orientation of the categorical content. Accordingly, the main function of innovation is to bring about positive changes in the cultural environment and to define it as a unit of creative-theoretical and subjectpractical activity of the subject, which is manifested in a wide echo.

The analysis shows that the study of the phenomenon of innovation in the scientific discourse of the twentieth century did not go beyond the technical and economic context. In particular, accordingly, innovation is widely understood in the structure of production as a technological innovation that brings economic benefits. Therefore, the concept of technicaleconomic paradigm emerges in the scientific environment. This concept implies "a set of interrelated technical, organizational, and managerial innovations whose benefits should be sought not only in the new range of products and systems, but also in the relative structure of funds that can be used to produce more" [14].

To date, the phenomenon of innovation has overcome the narrow scope of the technical and economic sphere. This can also be seen when innovation is applied in different areas of culture. Now, innovative activity is emerging as a key condition for development. The existence of educational, scientific, social, political, economic innovations indicates the nature of the desire for innovation that occurs in different spaces of society and culture. This, in turn, is a characteristic feature of modern socio-cultural reality.

The return of the past can only be repeated, taking on the appearance of novelty, the old, the previous thing, the events can be renewed, and only in the form of innovation can civil rights be acquired. From this point of view, the most valuable thing is innovation. Therefore, the traditional past tries to show that it is a novelty and the present in itself "[15].

\section{CONCLUSION}

Hence, innovation is a complex socio-cultural phenomenon that requires substantiation, first and foremost, in terms of its time. In short, the main source and subject of creativity is the creative person. A creative person is distinguished by the following qualities:

1. Perceptual traits (concentration of strangely meaningful attention), intellectual traits (intuition, fantasy, prediction, etc.), originality, perseverance, ability.

2. The dominant role of cognitive motivation, critical creative activity, the ability of the subject to find innovation, the ability to create standards of aesthetic, moral and intellectual ideals.

3. Intellectual activity that integrates mental and motivational factors.

4. Ingenuity in finding a problem, the ability to round out a long chain of feedback, the purposefulness of exposure, the readiness of memory, the ability to evaluate, the ability to easily apply ideas, 
the ability to round easily, the presence of a sense of humor.

5. Organic unity of high creative ability and motivational-creative activity.

6. To perform actions that go beyond ordinary events, but do not contradict the laws of nature, to feel what will happen in the future, rich imagination and intuition.

\section{REFERENCES}

1. Address of the President of the Republic of Uzbekistan Sh. Mirziyoyev to the Oliy Majlis. Tashkent, 03.02.2020

2. Balabanov I.T. Innovation Management St. Petersburg: Peter, 2000 - P. eleven.

3. Wewell W. History of the Inductive Sciences. -SPb., 1867-1869. T. 1-3. - 48 p.

4. Kryuchkova S.E. Innovations and their role in the modern world (Chapter in the collective monograph: "Synergetics nonlinearity - globalism." - $-\mathrm{M}$.: Publishing house of MSTU "Stankin", 2007.

5. Cherepanova NV Traditions and innovations: socio-philosophical analysis: Author. ... Cand. philol. sciences. -M., 2007. - P. 13 - 14.

6. Findlay C.S., Lumsden Ch.J. The Creative Mind. Towards an Evolutionary Theory of Discovery and Innovation // J. of Social and Biological Structures. 1988.Vol. 11. P. 10.

7. Findlay C.S., Lumsden Ch.J. The Creative Mind. Towards an Evolutionary Theory of Discovery and Innovation // J. of Social and Biological Structures. 1988.Vol. 11. P. 10.

8. Knyazeva EN From discovery to innovation: a synergistic view of the fate of scientific discoveries // Evolution, culture, knowledge. M., 1996.S. 77.
9. Krajukhin G.A., Shaibakova L.F. Innovations, innovative processes and methods of their stimulation: essence and content. - SPb., 1995 - S. 12.

10. Santo B. Innovation as a means of economic development: Per. with Hung. M .: 1990 - P.100.

11. Bestuzhev-Lada IV Predictive substantiation of social innovations. - $M$.: 1993 - S. 18.

12. See Barnett H.G. Innovation: The Basis of culture change. - N.Y., 1953.

13. Prigogine Al Modern sociology of organizations -M., 1995 -S. 185.

14. Freeman C. Preface to Part II // Dosi et al. (1988b: 10).

15. Krasnukhina E.K. Traditions and innovations as forms of social education. // Innovation and education. Collection of conference materials. Series "Symposium", issue 29 - St. Petersburg: St. Petersburg Phil-th Society, 2003 - p. 121. 